\title{
Internal Analysis of Forever 21's Failure in China
}

\author{
Jiarui Liu \\ The London School of Economics and Political Science, London, The United Kingdom \\ Email:amyliu_@outlook.com
}

How to cite this paper: Liu, J. R. (2021). Internal Analysis of Forever 21's Failure in China. Chinese Studies, 10, 147-155. https://doi.org/10.4236/chnstd.2021.103009

Received: May 22, 2021

Accepted: July 23, 2021

Published: July 26, 2021

Copyright (c) 2021 by author(s) and Scientific Research Publishing Inc. This work is licensed under the Creative Commons Attribution International License (CC BY 4.0).

http://creativecommons.org/licenses/by/4.0/

\begin{abstract}
Forever 21's bankruptcy sent an alarm to other players in the fast fashion industry. It failed because of its blind adherence to its outdated tactics and misinterpretation of the changes taking place in the industry. It mistakenly assumed that the fast fashion business always stays the same even though it operates in a sector that has one of the fastest-paced changes. Thus, a reflection on Forever 21's failure is a necessity before any one of the fast fashion brands treads on its heel. This study tries to provide an internal analysis of its failure in China. This study is divided into four parts. Part one is a general introduction, including the background and significance of the study. Part two is an analysis on Forever 21's failure based on its unique $S P A$ business mode. The internal analysis is separated into two parts, front and back ends, with an aim to provide a deeper knowledge on its production cycle. Part three introduces some recommendations to other industry players from three dimensions, including sustainability, strategies and design. Part four covers conclusions.
\end{abstract}

\section{Keywords}

Forever 21, Fast Fashion, Failure, SPA Model

\section{Introduction}

\subsection{Significance of the Study}

Forever 21, the once top fast fashion brand, filed for bankruptcy in 2019, bringing an end to its spectacular success story. The fall of Forever 21 signals changes taking place in the fast fashion industry that the target customers are changing attitudes towards their business modes. Tactics must be updated before the further loss of market share.

Many studies have been published to analyse the reasons behind Forever 21's 
failure. However, not many provide a comprehensive analysis on the internal reasons behind its failure, not to mention from a Chinese market perspective. This study is based on the status-quo in China and tries to examine the reasons behind Forever 21's retreat from Chinese market.

The following is what this study is trying to achieve:

1) Learn the internal reasons behind Forever 21's failure from its design to its retail channels. Unlike the usual $S W O T$ tactic, this study focuses on the brand's $S P A$ business model and analyzes the merits and demerits of every production procedure.

2) Give recommendations based on the current situation facing fast fashion brands from three dimensions, i.e., sustainability, strategies and design. Most studies only include one dimension. However, this study integrates other recommendations and gives some more suggestions available for fast fashion brands.

\subsection{Literature Review}

Relevant studies have evolved with the development history of fast fashion industry, from its birth, its peak to its fall. China has experienced a boom in fashion industry from 2006 to 2012. Early work has focused on understanding the mode behind fast fashion. An article written in 2008 praised $Z A R A$ for its innovation and quick response. Fast fashion brands like $Z A R A$ learned fashion trends fast and produced garments mimicking a top-class design but reasonable price in two weeks because of its strategy to manufacture within the Inditex Group (Xiao, 2008). Later in 2009, another study focused on SPA business mode and pointed out its core value, i.e., speed and profits. The article reviewed the rise of fast fashion as a product of the proliferation of fast-food culture (Yang, 2009). Later in the years, fashion brands came to realize a differentiation in customer groups in China. High salary residents do not share the same purchasing habit with those who are at the average level. Unlike their parents, young people have a different mindset towards consumption. The fast-food culture has been spreading, not only in fashion industry, but also in other industries that were once durable, like automobiles and laptops. It was a perfect time to enter markets for fast fashion, and new business modes like increasingly mature online shopping as well as group purchase (Hu, 2011). However, after a rapid expansion, fast fashion brands have slowed down. Despite the growing number of new brand names and their expansion to the $2^{\text {nd }}$ and $3^{\text {rd }}$-tier cities, the growth rate decreased by $20 \%$, signalling a change in Chinese market. During recent years, customers have become increasingly aware that materialism and environment preservation in fast fashion industry have raised problems (Liu, 2019). So many fast fashion brands that were once at the forefront of the industry chose to leave the Chinese market, such as New Look, Topshop and Forever 21. With the Generation $\mathrm{Z}$ becoming the main purchase power, they have their own judgement and a better knowledge of the fashion industry. They value personalization and sustainability. Besides, companies should also keep up with the fast growth of 
China's digital business (Xiao, 2020).

\section{Analysis of Forever 21's Failure}

\section{Introduction of SPA Business Model}

SPA refers to Specialty Store Retailer of Private Label Apparel and was first adopted by the American apparel company GAP. SPA is a vertically integrated system, with one company responsible for every step in the manufacturing and retail process, from product planning, design to retail sales. The goal is to reduce unnecessary costs and respond to customers' needs better and more quickly. Several fast fashion companies adopt SPA, including ZARA, H\&M and Forever 21 (Du et al., 2015).

\subsection{Analysis of the Front End}

\section{Marketing}

Though started in Los Angeles, Forever 21 has its footprints all over the globe. It has been expanding rapidly and always pays a considerable amount of money to rent a large space. Some of its stores are as large as a department store and become a local iconic spot. However, its revenue cannot cover the rent, and consequently, payment imbalance constantly occurs. Additionally, Forever 21 tried to bring customers closer through social media and its official website, which has constantly upgraded to become more user-friendly. Nonetheless, it spent money in areas other than brand delivery. Its competitors have adopted multiple ways to win customers, including cobranding, collaboration with designers or announcing regional product endorsers. Forever 21's strategies are too old and immature.

\section{Distribution and Retail}

Forever 21 has two main retails channels, its large physical stores and online shops. It has been expanding too rapidly, starting from 7 countries to 47 countries in just six years. Before it announced bankruptcy, it was still opening up more physical stores. In 2018, Forever 21's sales dropped by $20 \%$ to $25 \%$, making it even harder for the company to maintain its payment balance. It missed the new industry practice that focuses on cutting down on the number of big and expensive physical stores and opening mini-shops or small pop-up stores to keep in contact with customers and help them experience the brands before making purchase decisions online (Knowledge@Wharton, 2019). Moreover, Forever 21's bankruptcy has made it difficult for many malls, like Simon and Brookfield. Since the brand was one of the biggest tenants, the bust emptied more than 12,000 stores in the past two years, and it would be a challenge to refill these vacancies (Sustainable Brands, 2016).

\subsection{Analysis of the Back End}

\section{Design}

Forever 21 has a problem with the originality and authenticity of its products. 
It usually would take 3 to 6 months to turn an item from a design on the runways to the racks. However, Forever 21 has cut its production cycle down to weeks. Sometimes, before the original brands arrive on the shelves, it has already mass-produced the clothes with its large fashion houses' mode.

Forever 21 does not have designers. It steals everyone's work, from big brands like Anna Sui to smaller, independent designers like Trovata. Unlike ZARA, which has over 200 designers participating in the same streamlined production process, Forever 21 has a bunch of journeymen travelling worldwide and attending fashion shows so that the brand could duplicate the latest work. Because of this, Forever 21 has already been sued more than 50 times for copyright infringement. They would be forced to pay a considerable sum of money every time for settlement and finding ways to fix its declining public image before they were able to produce their own unique design or discover some talented independent designers who would love to work for the brand (Roll, 2018).

Just like how baffling it was for Forever 21 to expand its physical stores when its competitors were focusing on e-commerce, the brand's acts to steal the protected fabric print instead of the unprotected garment design sound even more confusing. Forever 21 has been adopting the strategy to steal something legally protected and leave the unprotected ones behind (Sauers, 2011).

The brand's design has another problem in the Chinese market. It failed to study the Chinese customers' taste well before launching its products. Its designs are popular in America, but Chinese young women are not comfortable with the mini-skirts or the hot tops with the least cloth. It should have invested more in studying customers and predicting local market trends.

\section{Manufacturing}

Many fast fashion brands share labour disputes. To keep their prices competitive, fast fashion brands cut down all kinds of costs, including labour and quality. Since these brands usually have many orders, one dollar saved from manufacturing garments would save the company millions of dollars. They relocate the manufacturing sections abroad to some places where labour is cheap and does not know how to protect human rights. People become disconnected from those who make their clothes, with $97 \%$ of the items made in underdeveloped or developing countries and regions like Bangladesh, India, Nepal and Southern China. Roughly 40 million garment workers in today's world do not share the equal rights and protection as customers do.

They made contracts with the local factories to mass-produce their clothes. With the fast fashion brands' aim to shorten the cycle from a fresh design to the rack with the lowest price tag, the workers, roughly $85 \%$ women, would have to accept the minimum wage and work over 10 hours every day in a dangerous building and filthy environment because they would otherwise lose this contract and find no way to support their family. Rana Plaza building collapsed in Bangladesh and killed more than 1100 workers there. Many workers have formed leagues to protest against the government so that they could receive a higher 
wage. However, they were too weak to save themselves from the exploitation and violation of the fast-fashion brands' profit-driven mindset. Forever 21 is just one example. The fast fashion industry has to save money, sacrificing the rights of workers and the product quality.

Additionally, sustainability movement is rising in the fashion industry because it has become one of the biggest polluters in the world, only second to oil. Fast fashion is to be blamed. People now consume around 80 billion new pieces of clothes every year and that figure is $400 \%$ more than the amount we consumed 20 years ago. The average UK shopper produces 70 kilograms of textile waste annually. The fashion industry is exhausting non-renewable energy, emitting vast amounts of greenhouse gases and injecting huge quantities of harmful chemicals into the environment (Sustainability.uq.edu.au., 2018). The chemicals used in cotton production would penetrate into our bloodstream when we wear those clothes. Leather production is one of the most toxic process. Workers are exposed to the harmful chemicals and studies have shown that they are facing a greater risk of cancer by 20\% 25\% (Morgan, 2015).

\section{Supply Chain}

Fast fashion brands have a strong supply chain with the help of the unique $S P A$ business model to ensure quick response. In the fast fashion industry, time is money. On average, a one-day delay for launching a new product would cause a $0.7 \%$ depreciation per day. If the brand sells the product 10 days ahead of its competitors, it can evade depreciation by $7 \%$ and gain a gross margin of $13 \%$.

Fast fashion brands' robust supply chain helps win market share in the first place. However, many foreign fast fashion brands' competitors in China can excel in supply chain management. Chinese players have been learning the successful practices of foreign fashion brands and have cultivated many talents to help them speed up the growth. For example, with the development of industrial networks, a new business model has been invented, C2M (Customer-to-Manufacturer), in China. The C2M practice eliminates the steps like inventory, distribution and promotion, and reduces the distance between customers and manufacturers with a quicker and more flexible response to customers' personalised requests. Brands with this business model are more efficient than foreign brands like Forever 21 and pose threats.

\section{New Business Development}

Forever 21 constantly creates and acquires new sub-brands in its brand architecture intending to tailor its products to a broader group of people. The brand is divided into ten sub-brands distinguished by styles, with all housed in typical huge Forever 21 retail stores. However, launching so many categories of clothes could only add costs, leading to problems like a pile-up of inventory and overwhelming customers with the countless options of clothes (Maheshwari, 2019). Sub-brands should not steal the spotlight of the leading brand. Changing the businesses too frequently would diminish its customers' loyalty to the brand because it became less committed to its original idea and lose its uniqueness (Roll, 
2018). The brand would be less focused on developing its primary business, and competitors would grasp the chance to surpass it. LEGO and Apple went through the same problem but survived because they later returned to the very beginning and stay focused on the one product.

\section{Recommendations to Fast Fashion Brands in China}

\subsection{Strategies}

\section{E-commerce}

Forever 21 failed because it overlooked the importance of e-commerce, which serves as a warning to the whole industry. China has the most developed e-commerce practices in the world, so effective growth marketing strategies for the brands' e-commerce platforms are essential.

E-commerce growth demands three elements, i.e., omnichannel, social media and big data. Fast fashion brands should make full use of all channels to interact with consumers and sell products, which include Taobao, the Red Book, mini programmes on WeChat. Social media management and cooperation with KOLs play the role of sending messages to consumers and narrowing the gap. KOLs could advise people on mix and match with the brand's garments or offer promo codes through live streaming. Fast fashion brands should pay attention to the tone and style of their social media to ensure that their brand image is consistent with the brand identity. To analyse the performance, collecting big data like conversion, clickthrough or engage rate is necessary to measure success with brand growth.

\section{Supply Chain Management}

The fast fashion industry demands rapid design-to-delivery, so solid logistics and supply chain are necessary. Missguided has a practice called 'near-shoring' to increase speed. The company places the production of trend pieces next to it to quickly respond to orders. It also has a wide supply network, enabling it to turn around products from other countries in under two weeks. The key is to keep their buying budget flexible for fast reaction. This goal could also be realised by limiting the materials needed to produce garments so that the company could buy in bulk and reduce the turnaround time.

A robust supply chain becomes even crucial with the development of live streaming e-commerce in China. One example is $\mathrm{C} 2 \mathrm{M}$, fast fashion brands should think reversely, from the consumer and streaming ends to understand the real needs so that they can create a supply chain that take the order before putting into production. Companies could choose to use machine learning technology to predict trend and then decide what to produce. Smart fashion brands would make full use of data to examine the purchase process, learn the best-selling products and predict the next trend. These algorithms have been increasingly accurate as they mature. For example, US retailer Revolve has been able to measure influencer impact and social engagement with the help of its own data tools, helping it win an $\$ 82$ million rise in profit for Q3 after a fall in 
Q2 (Remy et al., 2016). In this way, fast fashion brands can avoid the dilemma of the insufficient supply and pressure for high inventory.

\section{Brand Portfolio Strategy}

Although developing new businesses could be a way to expand in the market, managing different sub-brands is challenging. Fast fashion brands need to think carefully about their product portfolio to clearly identify the strategic and supporting brands. However, blindly creating 10 sub-brands like Forever 21 is never wise as it might cause consumer confusion and add communication cost. The best strategy is Less is More. Before adding a new sub-brand or creating a brand extension, it is critical to examine whether each brand performs a specialised role and occupies a distinct scope. The market coverage of the sub-brands should achieve the maximum market coverage with minimal overlap. Companies should analyse their own capabilities, i.e., whether they have the resource or knowledge to add a new line. To avoid inconsistency, they need to ensure that the new sub-brands are aligned with the direction of the original brand. Otherwise, it is always better to focus on the growth of the primary brand than considering brand portfolio strategy.

\subsection{High-Quality Design}

\section{Technologies in Fast Fashion Design}

Many companies have been using AI and data analysis technologies to detect real-time trends and produce a better design. Stitch Fix is a good example. It has been pioneering the AI-driven design, using its algorithms to recognise the trends and styles missing from its inventory and suggest new designs based on combinations of customer's tastes, and later get approvals from human designers (CB Insights Research, 2019). AI can help companies optimise strategic decisions and develop new business models. 3D design platform like CLO is another example of AI's assistance with making design more manageable and more flexible. Brands can change fashions the moment it starts production. Other technological innovations include removing the uncertainty around the size and fit by using AI to personalise customers' requirements and temperature-changing smart fabrics. Many more innovations are approaching, and fashion companies must take hold of the opportunities to stand at the forefront of the technology-driven fashion wave.

\section{Collaboration with independent designers}

Collaboration is a win-win strategy. Independent designers have distinct traits that can help the fashion brand gain more recognition. The designer can gain a reputation through working with a famous fast-fashion brand. For example, Adidas's new running shoe was designed by Alexander Taylor with plastic found in the ocean as its support of the lasting designs campaign.

\section{Conclusion}

Forever 21 faded because it assumed that the same tactics could last forever in a 
fast-paced industry, chose the wrong path to expand its business and missed the timing to restructure its business. Several changes have taken place in the fast fashion industry in China, including e-commerce (livestreaming), supply chain innovation (C2M) and sustainability awareness. To prevent market share loss, fast fashion brands need to respond quickly.

Fast fashion industry evolves rapidly, partly due to the technology development and partly because its target customers, Generation Z, have a changing mind. A growing awareness of environmental and IP protection among customers requires fashion brands to implement sustainability projects and create own high-quality design. They should invest wisely in technologies like AI and data analytics to make sure they can predict trends correctly, produce garments with flexibility and manage inventory with the minimum cost. Besides, more thorough analysis on the brand portfolio strategy before adding new sub-brands is necessary.

\section{Acknowledgements}

I cherish this chance to express my gratitude to many people without whose help and encouragement this thesis would not have been completed.

\section{Conflicts of Interest}

The author declares no conflicts of interest regarding the publication of this paper.

\section{References}

CB Insights Research. (2019). The Future of Fashion: Technology \& the Industry. https://www.cbinsights.com/research/fashion-tech-future-trends/\#prd

Du, H., Huang, Y., \& Liu, Y. (2015). The Analysis of the SPA Apparel Company Strategy. In 2nd International Conference on Civil, Materials and Environmental Sciences (pp. 726-729). Atlantis Press. https://doi.org/10.2991/cmes-15.2015.194.

$\mathrm{Hu}$, X. (2011). 消费群体分化下的新商机. Kns.cnki.net. https://kns.cnki.net/kcms/detail/detail.aspx?dbcode=CJFD\&dbname=CJFD2011\&filen ame $=$ XSYS201104018\&v $=$ pTM78KvnaDkL $\% 25 \mathrm{mmd2BEfjDj1hkgdZ2wJY \% 25mmd2B}$ pQcA\%25mmd2ByqMyyu7wozoMtW6XpaeJKFZDox8Sbj

Knowledge@Wharton. (2019). Fashion Fail: Where Did Forever 21 Go Wrong? https://knowledge.wharton.upenn.edu/article/where-did-forever-21-go-wrong/

Liu, B. (2019). Materialism, Environmental Awareness and the Logic of Fast Fashion Brand Consumption. Xml-data.org. http://www.xml-data.org/RWDL/html/20190114.htm

Maheshwari, S. (2019). Forever 21 Bankruptcy Signals a Shift in Consumer Tastes (Published 2019). Nytimes.com.

https://www.nytimes.com/2019/09/29/business/forever-21-bankruptcy.html

Morgan, A. (2015). The True Cost [Video]. Michael Ross.

Remy, N., Speelman, E., \& Swartz, S. (2016). Style That's Sustainable: A New Fast-Fashion Formula. Mckinsey.

https://www.mckinsey.com/business-functions/sustainability/our-insights/style-thats-s 
ustainable-a-new-fast-fashion-formula

Roll, M. (2018). Forever 21 - Fast Fashion Retail Brand with an Edge. Martin Roll. https://martinroll.com/resources/articles/branding/forever21-fast-fashion-with-an-edg e/s/articles/branding/forever21-fast-fashion-with-an-edge/

Sauers, J. (2011). How Forever 21 Keeps Getting Away with Designer Knockoffs. Jezebel. https://jezebel.com/how-forever-21-keeps-getting-away-with-designer-knockof-582276 $\underline{2}$

Sustainability.uq.edu.au. (2018). Fast fashion quick to cause environmental havoc. https://sustainability.uq.edu.au/projects/recycling-and-waste-minimisation/fast-fashio n-quick-cause-environmental-havoc

Sustainable Brands. (2016). Fast Retailing Applies Unique SPA Business Model to Help Forge Brighter Future in Bangladesh.

https://sustainablebrands.com/read/leadership/fast-retailing-applies-unique-spa-busine ss-model-to-help-forge-brighter-future-in-bangladesh.

Xiao, L. (2008). ZARA:究竟“快”在了哪里. Kns.cnki.net. https://kns.cnki.net/kcms/detail/detail.aspx?dbcode=CJFD\&dbname=CJFD2008\&filen ame $=$ FAZI200811030\&v=YG00vIqI35HTF1m0mVACpDu62H1XbQE13DKTJPzv2Nqt dRiPkm5qw3\%25mmd2B90\%25mmd2BSCEnk1

Xiao, W. (2020). 快时尚风向标正在悄悄改变. Gb.oversea.cnki.net. http://gb.oversea.cnki.net/KCMS/detail/detail.aspx?filename=ZGFS202001170040\&dbc ode $=$ CCND\&dbname $=$ CCND2020

Yang, D. (2009). SPA 的三大核心理念和具体运用分析. Kns.cnki.net. https://kns.cnki.net/kcms/detail/detail.aspx?dbcode=CJFD\&dbname=CJFD2009\&filen ame $=$ ZGFS200905025\&v=vWHWpvXfCaJ7nB0YJsiQ4FNSG6MTFTOSAjjf\%25mmd2 BU9rSwWVxS\%25mmd2BJV5zeHgrL8GmK2XUc 